\title{
Age similarities in the inertial properties of attention
}

\author{
LAWRENCE R. GOTTLOB and DAVID J. MADDEN \\ Duke University Medical Center, Durham, North Carolina
}

\begin{abstract}
Adult age differences in the mode of allocation of visual attention were investigated, using a visual search task with a circular display containing one target letter and seven distractor letters. In two experiments, a total of 56 younger adults ( $M=20$ years) and 56 older adults ( $M=66$ years) searched for a target appearing with equal probability at one of two cued locations. The first cue appeared $115 \mathrm{msec}$ before display onset, and the second cue appeared with display onset; distance between the two cued locations was varied. Target identification performance indicated that attention was inertial, in that reaction time for second-cued targets was related either to the area of the portion of the visual field containing possible target locations or to the mean path length of a serial self-terminating search. There were no age-related decrements in the allocation of visual attention.
\end{abstract}

In visual search and classification tasks, the effects of attention are reflected in the fact that items presented at some (attended) spatial locations are identified more efficiently than items presented at other locations. Although, in some instances, these effects are due to eye movements and to the decline in retinal acuity as a function of increasing eccentricity, attentional processing appears to be mediated by different neural systems than those underlying eye movements. Cortical regions, especially the frontal eye fields and the parietal cortex, appear to mediate the voluntary (attentional) orienting of the visual system, whereas reflexive visual orienting is mediated by midbrain structures (Rafal \& Robertson, 1995).

Behavioral investigations suggest that attending to specific spatial locations involves selectively allocating processing resources to items presented at the attended locations. It is well established that presenting a visual cue (such as a bar marker) prior to a visual display can facilitate the identification of items at the cued location and impair the identification of items at noncued locations (Eriksen, 1990). The cuing effects are evident when the stimulus onset asynchrony (SOA) between the cue and the display is sufficiently brief to prevent eye movements. In addition, the presentation of a spatial cue regarding target location facilitates performance even for single-item displays, which implies that the cue influences target identification by directing the allocation of processing

This research was supported by Postdoctoral Training Grant T32 AG00029 and by Research Grant R37 AG02163 from the National Institute on Aging. We are grateful to Laura Denny, Amy Harris, Corri Oenbring, and Kim Hay for technical assistance and to Carl Pieper for statistical assistance. Thanks also to Gregory R. Lockhead for helpful comments on a previous version and to Charles W. Eriksen for both his helpful comments and permission to reproduce his data in Figure 1. Correspondence concerning this article should be addressed to $\mathrm{L}$. R. Gottlob, Box 2980, Duke University Medical Center, Durham, NC 27710 (e-mail: Irg@geri.duke.edu).

-Accepted by previous editor, Myron L. Braunstein resources (Henderson, 1996; Luck, Hillyard, Mouloua, \& Hawkins, 1996), rather than by simply reducing the uncertainty of target location (Duncan, 1980; Shiu \& Pashler, 1994).

The spatial distribution of attention has been described most frequently in terms of either a gradient or a spotlight. Gradient models characterize the distribution of attention as a continuum with a peak (representing the maximal rate of information extraction) at the focus of attention (Henderson \& Macquistan, 1993; LaBerge \& Brown, 1989; LaBerge, Brown, Carter, Bash, \& Hartley, 1991). Spotlight models describe attention as being relatively restricted in spatial extent but movable (Eriksen \& St. James, 1986; Eriksen \& Yeh, 1985). Although, in many contexts, these classes of models are difficult to distinguish empirically, it is easier for gradient models to account for changes in performance at noncued locations in response to either the spatial extent of the cued area (Henderson, 1991) or the validity of the cue (Madden, 1992). Observers are apparently able to attend to more than one display location simultaneously (Castiello \& Umiltà, 1992; Hahn \& Kramer, 1995), which is also more compatible with gradient models than with spotlight models.

\section{Inertial Versus Noninertial Attention Shifts}

Spatial attention has a dynamic component, in that the focus of attention (i.e., the peak of the processing gradient or the location of the spotlight) can change in location (shift) according to observer strategies and the informational properties of the display (Handy, Kingstone, \& Mangun, 1996). Several investigations of cuing effects have examined whether the shift of the attentional focus is inertial or noninertial. In general terms, if attention has inertial properties, it means that there is a spatial metric that imposes limitations or costs on its allocation or movement. For instance, according to an inertial shift of attention, the time required to change locations in the visual field is related to the distance of the shift. In contrast, the key feature of a noninertial shift (Kwak, Dagenbach, \& 
Egeth, 1991; Sagi \& Julesz, 1985) is that that the focus of attention may appear at different locations without regard to the distance between them. The critical confirmation of a noninertial shift would be that shift distance is independent of time, assuming that it can be confirmed that there is an actual attention shift and not a parallel processing of target locations (Kwak et al., 1991). Inertial shifts have been called analogue (i.e., analogous to a spotlight; Shulman, Remington, \& McLean, 1979; Tsal, 1983), and noninertial shifts have been called quantal (Sperling \& Weichselgartner, 1995) or discrete (Remington \& Pierce, 1984).

An analogous distinction may be made between inertial and noninertial aspects of attentional gradients. For instance, an inertial gradient would have spatial limitations, such as smaller amounts of attentional resources at the periphery than at the center or a dependence between area covered and density of resources. In contrast, a noninertial gradient would correspond to parallel processing of the entire relevant portion of the visual field, without regard to spatial limitations, as might be implied by certain object-based accounts of attention (e.g., Duncan, 1984).

Some cognitive operations, such as those involved in mental rotation (Cooper, 1976), appear to be inertial, in that reaction time (RT) is a linear function of the angular disparity between the stimuli to be compared. This mental analogue of rotation may be due to the necessity of representing intermediate (partially rotated) stimuli in order to reduce computational demands. Similarly, an inertial shift of attention may be employed in the process of visual search, in cases in which it is expected that the target lies somewhere along a scan path. Evidence for an inertial movement of attention was reported by Tsal (1983), who found that, in a location-cuing task, the asymptotic SOA (the time required for attention to reach the target) increased as the distance of the target from fixation increased from $4^{\circ}$ to $12^{\circ}$ (see, also, Shulman et al., 1979). Other investigations, however, have supported the conclusion that attentional movements are noninertial. Remington and Pierce (1984) also used location cuing but found that cuing effects were established by an SOA of $150 \mathrm{msec}$ for locations between $2^{\circ}$ and $10^{\circ}$, suggesting that the velocity of the attentional movement was proportional to the target distance. ${ }^{1}$ Sagi and Julesz (1985) reported that discrimination accuracy for $\mathrm{T}$ and $\mathrm{L}$ targets was constant for interletter distances up to $24^{\circ}$ (except for some lateral masking between adjacent targets), consistent with a noninertial movement of attention. Kwak et al. (1991) obtained similar results for RT measurements of letter discrimination, for interletter distances up to $9^{\circ}$. In a related paradigm-rapid serial presentation with multiple streams of stimuli-Sperling and Weichselgartner (1995) found that attention could move in a quantal fashion, without interference from an intervening stream of distractors.

A common feature of the investigations by Remington and Pierce (1984), Sagi and Julesz (1985), and Kwak et al. (1991) is that the target items were presented in an otherwise empty display. Eriksen and Webb (1989) reported evidence for noninertial movement of attention in a paradigm in which the display contained nontarget items as well as target items. In two experiments, Eriksen and Webb used a version of visual search in which two display positions of an eight-letter circular display were cued. One of two preassigned target letters always occurred at one of the cued locations. In both experiments, RT did not vary significantly as a function of the number of nontarget letters separating the cued positions, indicating a noninertial movement of attention. Eriksen and Webb proposed that, although the attentional movement was noninertial, processing of the display positions was serial: When one of the two cues preceded the onset of the display (and the second cue) by $50 \mathrm{msec}$, RT was higher for targets associated with the second cue than for those associated with the first cue, and this effect did not interact with the number of display positions separating the cues. Kwak et al., using a different methodological approach (the subadditivity diagnostic; Egeth \& Dagenbach, 1991), also concluded that attentional movement was both serial and noninertial. Kwak et al. pointed out that, if one is trying to assert that attention moves in a noninertial manner, it is necessary to show that attention does in fact move - that is, the locations are not being processed in parallel.

One purpose of the present experiments was to examine more closely some possible departures of the Eriksen and Webb (1989) data from the noninertial model. Although Eriksen and Webb found that the effect of intercue distance was not significant statistically for either RT or error rate, some changes in performance as a function of intercue distance are noticeable. The data from Experiment 2 of Eriksen and Webb are reproduced in Figure 1. This figure reveals that, for targets located in the second-cued position, there was an increase in RT (of approximately $20 \mathrm{msec}$ ) when the two cues were separated by one display position, as compared with other intercue distances. The error rate in this condition was also higher $(19 \%)$ than those for other second-cued targets $(11 \%-$ $15 \%)$. There may, consequently, be some reliable changes in performance associated with intercue distance that were not significant statistically in the Eriksen and Webb data.

\section{Age Differences}

In addition to exploring inertial versus noninertial properties of attention, the purpose of the present experiments was to investigate age-related differences in attention, by comparing the performances of two groups of observers: younger adults (ages 18-22) and older adults (ages 60-70). As humans age, the brain undergoes physical changes, most notably through unevenly distributed reductions in the volume of gray matter, heavily concentrated in (but not confined to) the prefrontal cerebral cortex (Raz et al., 1997). These diffuse physical changes apparently lead to changes in neural function (Grady et al., 1995; Madden et al., 1997), which are believed to be responsible for many age-related changes in cognitive func- 


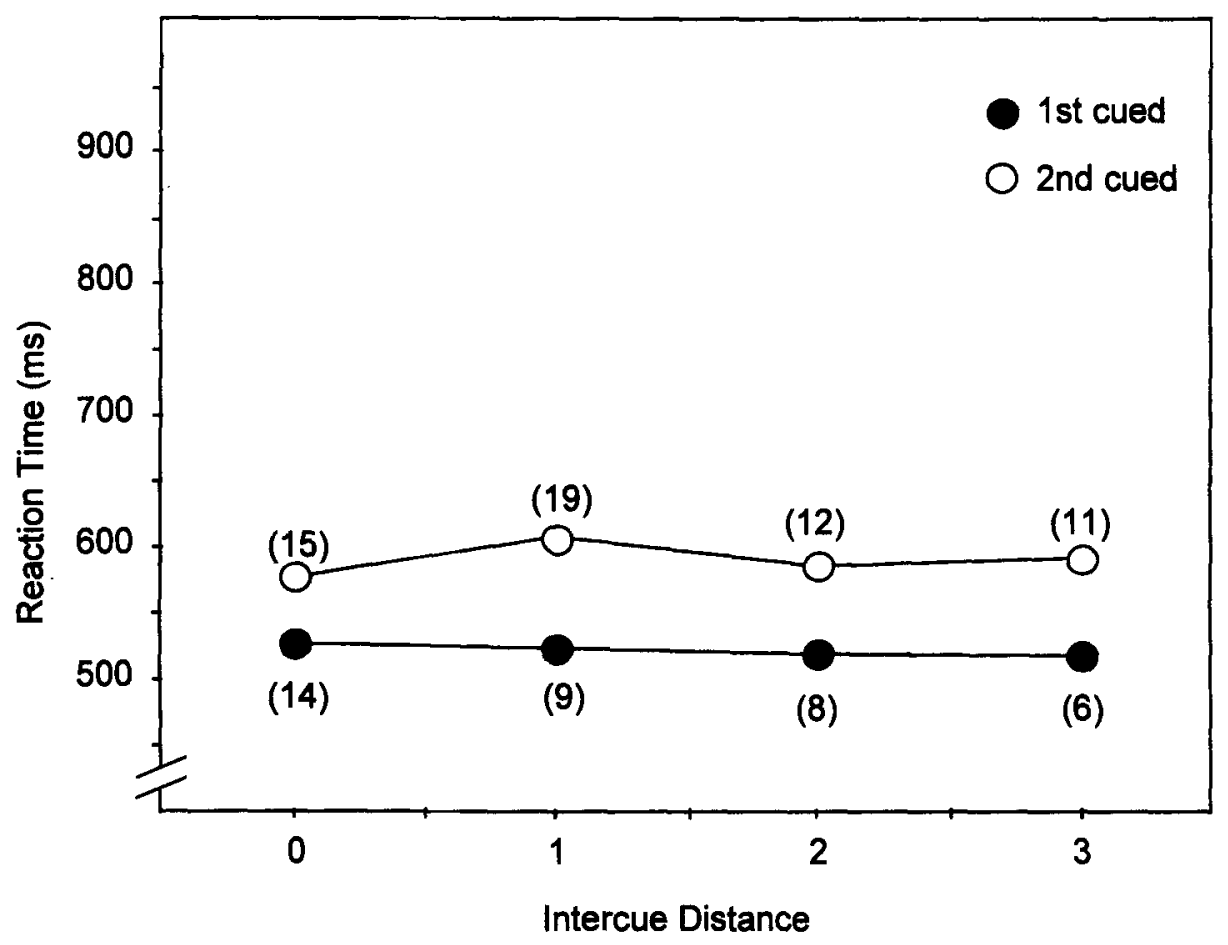

Figure 1. Mean reaction times on correct trials and error rates (numbers next to symbols) as a function of first- versus second-cued trials in Eriksen and Webb (1989, Experiment 2).

tioning. One parsimonious description of these functional changes is that of generalized slowing (Salthouse, Fristoe, Lineweaver, \& Coon, 1995), according to which a single influence, diffuse slowing of mental processing, is responsible for changes across a wide variety of cognitive tasks.

The null hypothesis expressed by generalized slowing is that all cognitive processes are slowed, as a function of age, to a comparable degree. This hypothesis is often tested through examination of Brinley plots (Brinley, 1965), which are $x-y$ scatterplots used to relate older mean RT ( $y$-axis) to younger mean RT ( $x$-axis) in a number of task conditions with varying time demands. The relationship between older and younger mean RTs can often be characterized in terms of a regression function. If a linear regression produces a slope of 1 , indicating that time changes across tasks are the same between age groups, it is inferred that both age groups are completing the relevant cognitive operations with the same speed. If the regression slope is greater than 1 , it is inferred that older adults incur greater absolute time costs and benefits and, thus, are operating more slowly than younger adults. If a single best-fit regression line produces the most parsimonious description of the data, it is inferred that a single slowing factor is sufficient to explain the age group differences. The Brinley plot consistent with predictions of generalized slowing would produce a slope greater than 1 , with a positive $y$-intercept. In many cases, linear functions have been sufficient to characterize the relationship between age group performances, although Myerson, Hale, Wagstaff, Poon, and Smith (1990) have argued that curvilinear functions more accurately represent the mechanisms responsible for age-related slowing.

Investigations of age-related changes in visual attention have indicated that the allocation of attention to specific display positions is, in many contexts, similar for younger and older adults. The magnitude of locationcuing effects, for example, is frequently found to be comparable for younger and older adults (Gottlob \& Madden, 1998; Hartley, 1992; Madden \& Plude, 1993). The ability to split attention between two noncontiguous display locations also appears to be relatively resistant to age-related decline (Hahn \& Kramer, 1995). The division of attention in dual-task paradigms, however, has been found to be less efficient for older adults than for younger adults (Salthouse, Rogan, \& Prill, 1984; Whiting \& Smith, 1997). In some cases, this age difference can be ascribed to age-related slowing of cognitive performance associated with the individual tasks (i.e., generalized slowing; Salthouse et al., 1995). In other cases, the pattern of age differences in dividing attention is not consistent with generalized slowing (Madden, 1986).

Age differences in the movement of focused attention have been investigated in several experiments. Madden (1992) applied an allocation model (Eriksen \& Yeh, 1985) to younger and older adults' performance in a visual search task with target location cues. The movement of attention between display locations was estimated to be 
slower for older adults ( $215-247 \mathrm{msec}$ ) than for younger adults (124-168 msec). Madden, Connelly, and Pierce (1994), however, demonstrated that this apparent agerelated increase in the time required to shift attention may be due to the time required to process a nontarget display item in the cued display position. When the display contained only the target item, Madden et al. (1994, Experiment 1) found that the estimated time to shift attention was not significantly different from $0 \mathrm{msec}$ for either younger adults or older adults. Madden (1990) reported similar findings: When a target item was not accompanied by nontarget items in the display, the effect of cue-target SOA, between 50 and $183 \mathrm{msec}$, was minimal for both younger and older adults. The presence of nontarget display items, however, led to an age-related increase in the time required to use the cue effectively.

The Madden (1990) and Madden et al. (1994) findings suggest that, when the target is not accompanied by other display items, shifts of visual attention may be best characterized in terms of a serial noninertial model (Eriksen \& Webb, 1989; Kwak et al., 1991), for both younger and older adults. The interpretation of the age differences reported previously for multi-item displays is less straightforward. The presence of nontarget items may require relatively more processing time for older adults than for younger adults. One goal of the present experiments was to determine whether a serial noninertial model of attentional movement could continue to account for both younger and older adults' performance, when the task involved multi-item displays. The experiments all involved a search task developed by Eriksen and Webb, in which two display locations are cued sequentially. As was noted previously, Eriksen and Webb concluded that their data supported a noninertial model, in that RT was constant as a function of the number of display items separating the cues.

\section{EXPERIMENT 1}

In Experiment 1, we used a sequential-cuing methodology (Eriksen \& Webb, 1989) to examine age differences in the movement of focused attention in multi-item displays. In this experimental design, attention is first cued to one location, then to a second location. A general prediction, consistent with Eriksen and Webb, would be for the presence of a sequence effect on discrimination RT: RT would be lower on trials in which a target appears at a first-cued location than on trials in which a target appears at a second-cued location. The sequence effect would presumably be due to the tendency of attention to be located at the first-cued location and not the secondcued location, when the target display appears. If there is a sequence effect, the pattern of RTs across distance conditions would possibly be diagnostic of inertial versus noninertial mechanisms of shifting attention: If attention is inertial, as intercue distance increases, second-cued RT should increase (assuming constant first-cued RT across distance). In contrast, if attention is noninertial, the second-cued RT-distance function should be approximately flat, as in Eriksen and Webb.

To increase the clarity of the displays, especially for the older adults, the displays in Experiment 1 were larger in size and presented for a longer duration than those of Eriksen and Webb (1989). In this experiment, we used elliptical displays (owing to equipment limitations, they were not precisely circular) that were $7.6^{\circ} \times 6.9^{\circ}$, as compared with the $2^{\circ}$ circular displays used by Eriksen and Webb. This difference should not be critical, because Kwak et al. (1991) reported RT to be constant as a function of interitem distance up to $9^{\circ}$. The stimulus durations were $115 \mathrm{msec}$ for the cue and $745 \mathrm{msec}$ for the display, versus a 50-msec cue and 150-msec display in the Eriksen and Webb experiments.

The sequential-cuing methodology was expected also to provide information on age-related differences in attention. If the movement of attention is serial and noninertial for both younger and older adults (Madden, 1990; Madden et al., 1994), both age groups should exhibit more efficient search performance for first-cued targets than for second-cued targets, and the difference between first- and second-cued RTs should be constant as a function of intercue distance. In contrast, a generalized agerelated slowing of attentional processes (Salthouse, 1996; Salthouse et al., 1995) would lead to an increase in the magnitude of the effect of intercue distance for older adults (relative to younger adults), possibly resulting in different second-cued RT-distance patterns across age groups. Age-group-related slowing might also be revealed in a Brinley plot, most likely by a best-fit linear regression slope greater than 1 .

\section{Method}

Observers. Thirty-two younger adults (18-22 years of age) and 32 older adults $(60-70$ years of age) participated. There was an equal number of men and women in each age group. The younger adults were Duke University students (who participated for course credit), and the older adults were relatively healthy, communitydwelling members of the Duke Aging Center Subject registry, with a minimum of 12 years of education (who were paid for their participation). The Vocabulary and Digit Symbol Substitution subtests of the Wechsler Adult Intelligence Scale-Revised (WAIS-R; Wechsler, 1981) were administered to all the observers. Corrected near visual acuity was measured binocularly with a Keystone Ophthalmic Telebinocular Vision Tester. Acuity ranged between $20 / 15$ and 20/40 for all the observers. Observer characteristics are listed in Table 1.

Apparatus and Stimuli. The stimuli were presented on a video graphics adapter (VGA) color monitor, operating at $70 \mathrm{~Hz}$, controlled by a 386-processor computer. Durations of trial events were multiples of the monitor refresh cycle time, which was $14.29 \mathrm{msec}$. The contrast and brightness controls were set at the normal level. The stimuli were white letters presented on a cyan blue background. Luminance of the stimuli was $44 \mathrm{~cd} / \mathrm{m}^{2}$, and that of the background was $15 \mathrm{~cd} / \mathrm{m}^{2}$, yielding a Michelson contrast for the stimuli of 49 . Responses were recorded from an IBM-compatible keyboard and timed from the onset of a monitor refresh cycle. Desk lamps provided normal room illumination.

The task and stimuli were similar to those of Eriksen and Webb (1989, Experiment 2), and the sequence of events on each trial is illustrated in Figure 2. The task was a two-choice version of visual search in which observers decided which one of two target letters 
Table 1

Observer Characteristics

\begin{tabular}{|c|c|c|c|c|c|c|c|c|}
\hline \multirow[b]{3}{*}{ Characteristic } & \multicolumn{4}{|c|}{ Experiment 1} & \multicolumn{4}{|c|}{ Experiment 2} \\
\hline & \multicolumn{2}{|c|}{ Young } & \multicolumn{2}{|c|}{ Older } & \multicolumn{2}{|c|}{ Young } & \multicolumn{2}{|c|}{ Older } \\
\hline & $M$ & $S D$ & $M$ & $S D$ & $M$ & $S D$ & $M$ & $S D$ \\
\hline Age (years) & 18.8 & 0.9 & 65.2 & 2.9 & 22.2 & 3.2 & 67.2 & \\
\hline Acuity & 15.9 & 2.0 & 20.8 & 6.7 & 15.8 & 1.9 & 22.3 & \\
\hline Education (years) & 12.8 & 0.9 & 17.4 & 1.7 & 15.0 & 1.8 & 16.6 & \\
\hline Vocabulary & 58.4 & 4.0 & 59.6 & 4.4 & 55.6 & 12.6 & 61.2 & \\
\hline Digit symbol & 73.0 & 10.0 & 57.4 & 9.6 & 75.9 & 19.4 & 56.9 & 10. \\
\hline
\end{tabular}

Note-Acuity, denominator of the Snellen fraction for corrected near visual acuity; vocabulary, raw score on WAIS-R Vocabulary subtest; digit symbol, raw score on WAIS-R Digit Symbol Substitution subtest. In Experiments 1 and 2, young and older adults differed significantly on all variables (except vocabulary in Experiment 1 ), at $p<.05$, by $t$ test. Number of observers $(n)=32$ per age group in Experiment 1 and 24 per age group in Experiment 2.

( $H$ and $N$ ) was present in a display of eight letters (i.e., one target and seven nontargets). The display characters were arranged in an ellipse with a $7.6^{\circ}$ vertical major axis and a $6.9^{\circ}$ horizontal minor axis, at a viewing distance of approximately $40 \mathrm{~cm}$. Individual display characters subtended approximately $0.9^{\circ} \times 0.9^{\circ}$ at this viewing distance. The nontarget letters were $M, W$, and $A$; in each display, two of these distractors occurred twice, and one occurred three times, balanced across blocks so that total occurrence was equal for each letter.

Each trial began with the presentation of a 1-sec fixation square, followed by a 244-msec blank screen. A single cue, composed of a black diamond shape $0.9^{\circ}$ in width, was then presented for $115 \mathrm{msec}$, at a location adjacent to one of the display positions (outside of the ellipse). At the offset of this first cue, the eight-letter display was presented. The display was accompanied by a second cue, of the same size and shape as the first cue, adjacent to one of the display positions not indicated by the first cue. The onset of the second cue was coincident with the onset of the display, and duration of these stimuli was $745 \mathrm{msec}$. The dependent variable of primary interest was RT, and pilot studies indicated that the $745-\mathrm{msec}$ display duration allowed older adults to maintain their error rate below approximately $5 \%$. The $H$ and $N$ targets were assigned to the "Ctrl" and "Alt" keys, located on opposite sides of the computer keyboard, and the observers pressed the key indicating their decision as quickly as possible following display onset. The observers rested the index finger of each hand on the response keys throughout the experiment.

On each trial, a target letter was located in one of the two cued positions of the display. We refer to the location of the target in the first-versus the second-cued position as the sequence variable (i.e., location of the target in the sequence of cued positions). Intercue distance, defined as the number of intervening display locations between those corresponding to the first and second cues, had four values: $0,1,2$, and 3 . The value of intercue distance was constant within each block of trials and was varied across blocks (as it was in the Eriksen \& Webb, 1989, experiments).

The following variables were orthogonal within each trial block: target $(H$ or $N$ ), target location (eight possible), sequence (first-cued or second-cued), and direction of the first-cued location with respect to the second-cued location (clockwise or counterclockwise). Each trial block had one occurrence of each combination of these variables (in a randomized order), for a total of 64 trials. Arrangement of the distractors $(M, W$, and $A)$ was varied pseudorandomly across trials, so that two adjacent positions were not occupied by the same letter. Four block orders were constructed so that, across the orders, each of the four levels of the intercue distance variable occurred once at each serial position in the block order. Within each age group, 8 observers were tested with each block order. These 8 individuals included two men and two women for each assignment of targets to response keys.

Procedure. Each observer performed the task in a single session of approximately $1 \mathrm{~h}$. The experimenter explained the task verbally, indicating that the observer was to respond as quickly as possible, while still maintaining accuracy. The observer was informed of the intercue distance at the beginning of each block. Each of the four trial blocks consisted of 32 practice trials (performed first), plus 64 experimental trials. On error trials (which were not rerun), the program paused until the observer pressed the space bar.

\section{Results}

Mean reaction times. Mean RTs for correct responses, as a function of sequence and intercue distance, are presented in Figure 3 for both age groups. RTs less than $150 \mathrm{msec}$ or greater than $2,500 \mathrm{msec}$ were trimmed, which eliminated fewer than $1 \%$ of the responses in each age
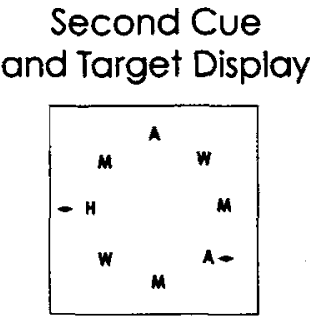

Target at First-cued Location

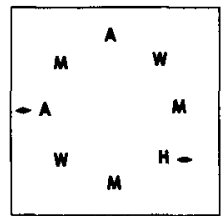

Target at Second-cued Location

$745 \mathrm{~ms}$

Figure 2. The order of events in Experiments 1, 2, and 3. Number of display items intervening between firstand second-cued positions was blocked in Experiments 1 and 3 and random in Experiment 2. 


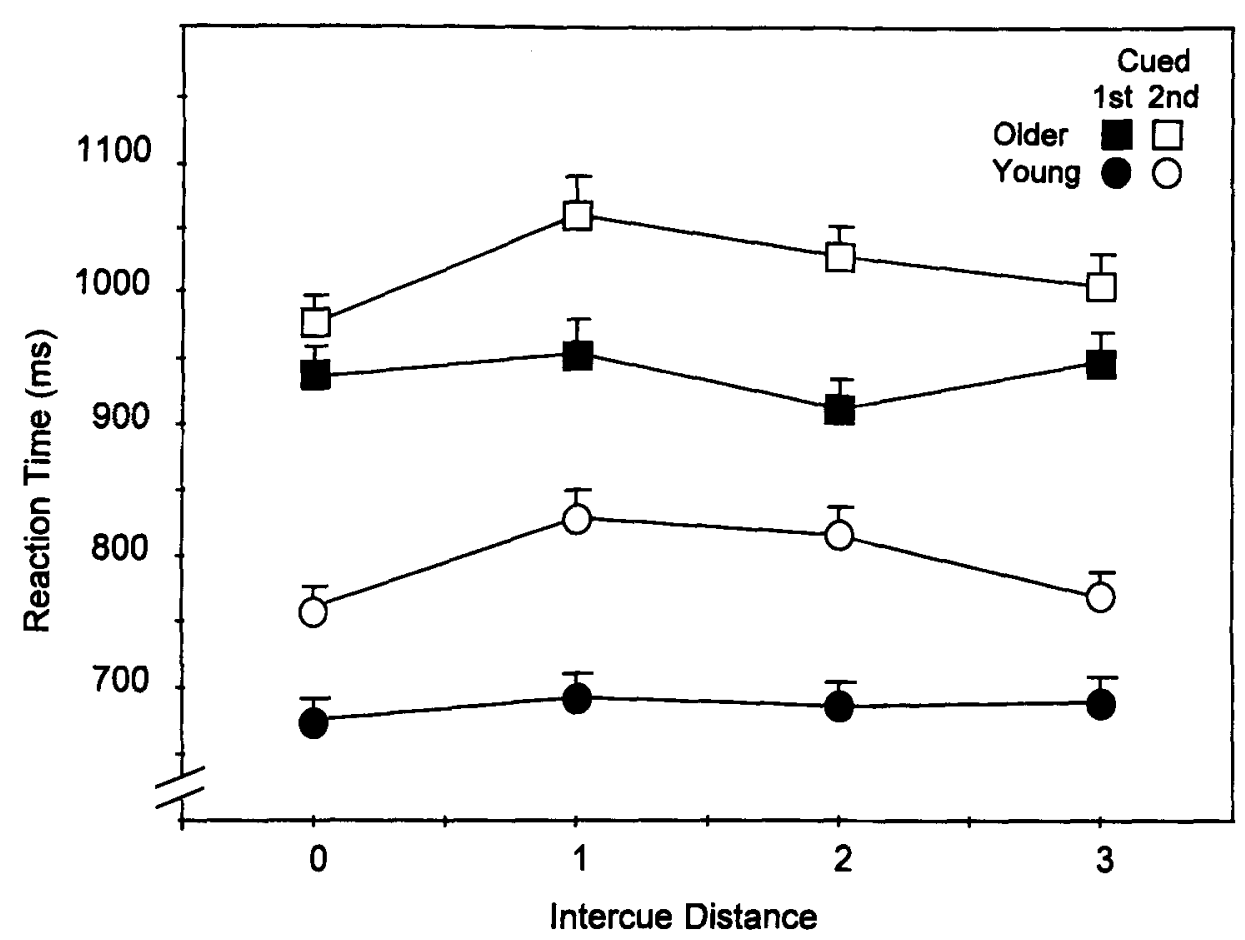

Figure 3. Mean reaction times on correct trials as a function of first- versus second-cued trial for Experiment 1, for the two age groups.

group (this RT trimming was performed in all of the presently reported experiments). A repeated measures analysis of variance (ANOVA) was performed on these RTs, with age group as a between-subjects variable and distance $(0,1,2$, or 3$)$ and sequence (first-cued vs. second-cued) as within-subjects variables. The alpha level for all tests was set at .05. Power analyses (Cohen, 1988) indicated that, at alpha $=.05$, there was a greater than .80 power to detect an effect size $(f)$ of .36 for the main effects of age group and sequence and the age group $\times$ sequence interaction. There was also a greater than .80 power to detect an $f$ of .25 for the main effect of distance and for all interactions involving this variable. According to Cohen, small, medium, and large effect sizes in this type of design correspond to $f$ values of $.10, .25$, and .40 , respectively.

In the ANOVA on RT, all of the main effects were significant. The age group main effect $[F(1,62)=78.09$, $\left.M S_{\mathrm{e}}=92,617\right]$ represented a higher mean RT for older adults $(977 \mathrm{msec})$ than for younger adults $(739 \mathrm{msec})$. The sequence effect $\left[F(1,62)=177.38, M S_{\mathrm{e}}=6,349\right]$ represented faster responses to targets associated with the first cue $(811 \mathrm{msec})$ than to those associated with the second cue $(905 \mathrm{msec})$. The age group $\times$ sequence interaction was also significant $\left[F(1,62)=4.0, M S_{\mathrm{e}}=6,349\right]$, because the RT advantage for first-cued targets was greater for younger adults $(108 \mathrm{msec})$ than for older adults $(80 \mathrm{msec})$. The distance main effect $[F(3,186)=10.27$,
$\left.M S_{\mathrm{e}}=6,349\right]$ indicated a variation in $\mathrm{RT}$ as a function of the number of display positions separating the cues.

The distance $\times$ sequence interaction $[F(3,186)=$ $\left.29.86, M S_{\mathrm{e}}=1,134\right]$ suggested that the change in RT as a function of intercue distance was different for firstcued and second-cued targets. Paired comparisons were performed with $t$ tests adjusted by the Sidak correction (Games, 1977) to control for Type I error rate. For targets associated with the first cue, the simple main effect of distance was significant $\left[F(3,186)=2.94, M S_{\mathrm{e}}=2,835\right]$, but Sidak $t$ tests indicated that no pair of intercue distance values differed significantly. The simple main effect of distance was also significant for second-cued targets $\left[F(3,186)=24.63, M S_{\mathrm{e}}=2,994\right]$; as is evident in Figure 3, there was a pronounced increase in RT for second-cued targets that were separated from the first-cued position by either one or two intervening positions. Sidak paired comparisons indicated that, on the second-cued trials, mean RT was comparable for Distance $0(868 \mathrm{msec})$ and Distance $3(887 \mathrm{msec})$ and for Distance 1 (943 msec) and Distance $2(921 \mathrm{msec})$ but that all other paired comparisons differed significantly (minimum difference $=$ $26 \mathrm{msec}$ ). A Brinley plot, as described in the introduction, yielded the following best-fit linear regression line: $\mathrm{RT}_{\text {older }}=407 \mathrm{msec}+.77\left(\mathrm{RT}_{\text {younger }}\right) ; r^{2}=.91$.

Error rate. The mean error rate was low for both younger adults $(2.9 \%)$ and older adults $(4.6 \%)$. The pat- 
tern of error rates (Table 2) was similar to the RT effects and did not suggest any speed-accuracy tradeoffs.

\section{Discussion}

Our goal in Experiment 1 was to determine whether there would be serial noninertial effects of attention in a display with distractors present and to investigate any age group differences in the movement or allocation of attention. We summarize our findings and interpretations here: We replicated Eriksen and Webb's (1989) results in the pattern of data, but whereas they concluded that the effects of attention were noninertial, our conclusion is that the effects of attention in the present experiment are inertial. However, we found that attention was inertial not with respect to intercue distance, but rather with respect to two alternative metrics: area determined by possible target locations and mean search path length. We will show that our results, thus, were compatible with either gradient or serial self-terminating (SST) models of attention. Also, we found that the allocation or movement of attention was similar across age groups in almost all respects.

Age differences. Although older adult RT was significantly higher than young adult RT, the only significant age group interaction was that for age $\times$ sequence: The sequence effect (second-cued RT minus first-cued RT) was $108 \mathrm{msec}$ for younger adults and $80 \mathrm{msec}$ for older adults. This age-related decrease in size of sequence effect was consistent with several possibilities. On first-cued trials, younger adults could have received more benefit from the first cue and/or less penalty from the second cue than did older adults. On second-cued trials, younger adults could have received less benefit from the second cue and/or more penalty from the first cue than older adults. In previous research examining the response to an abrupt-onset cue (using cues and cue-target intervals similar to those in the present experiment), S. S. Steinman, B. A. Steinman, Trick, and Lehmkuhle (1994) found that younger adults had a faster and more pronounced response than older adults. Therefore, it is most likely that younger adults were allocating more attention to the first-cued location than were older adults; this difference could have been due to strategy or to properties of attention. As was noted in the introduction, the null hypothesis consistent with generalized slowing is that all the components of a process are slowed (magnified) by a single factor; when applied to the size of a sequence effect, generalized slowing would predict a smaller effect size for younger adults than for older adults. In addition, this age group reversal of cuing effect size is inconsistent with much of the previous location-cuing literature, which has typically found that cuing effects either remain the same or increase with age (e.g., Gottlob \& Madden, 1998; Greenwood, Parasuraman, \& Haxby, 1993; Hartley, Kieley, \& Slabach, 1990).

As can be seen in Figure 3, the patterns of RT are similar across age groups, for both first- and second-cued trials. On the second-cued trials, both age groups have the same peaked pattern, in which the RT for the Distance 1 and 2 conditions are highest; this pattern will be examined in a subsequent section. Furthermore, in addition to the patterns of change in RT, the amounts of change in RT across distance are comparable across groups. These similarities indicate that both age groups allocated attention to second-cued locations in the same manner, with the same spatial characteristics, therefore providing no evidence of age-related decrement.

Performance across age groups may also be characterized by the best-fit regression line of the Brinley plot, which featured an intercept of $407 \mathrm{msec}$ but a slope of only 0.77 . This slope is incompatible with generalized slowing accounts (e.g., Cerella, 1985), which would predict slopes greater than 1 ; however, some previous studies have produced Brinley plot slopes on the order of 1 (e.g., Madden, 1984, 1985; Madden \& Gottlob, 1997). A slope of less than 1 would indicate that the increase in mean RT across task conditions was less pronounced for older adults than for young adults. The positive $y$-intercept of $407 \mathrm{msec}$, however, indicates that older adults had a greater overall RT than did younger adults. Common to both age groups was the unique pattern of sequence and distance effects, which indicated that observers were allocating attention, although perhaps not in the predicted manner that would have produced either flat or monotonically increasing RT-distance functions.

Sequence and distance effects. A sequence effect was observed, in that targets at the first-cued locations were identified more quickly than targets at the second-cued locations. This result is evidence that the first cue led to the allocation of attention. On second-cued trials, in which the target did not appear at the first-cued location, additional attentional movement and/or processing of the target was required before a response could be generated. Strictly speaking, this main effect of sequence is compatible with both serial spotlight and parallel gradient models. In a serial model, the sequence effect would reflect the order in which locations were attended, whereas in a parallel model, the sequence effect would correspond to the relative amounts of resources allocated to the various locations. A purely serial process would entail that only one target location was being processed at a time. Because the possibility existed that the nonattended location was also being processed concurrently, albeit at a lower rate, we could not establish that the sequence effect represented a purely serial shifting of an attentional spotlight. This nonidentifiability between serial and parallel processes has been well established (Townsend \& Ashby, 1983). Without loss of generality, we can view the sequence effect as reflecting an ordering of the processing completion times (first-cued, then second-cued).

The distance effect also has important implications for inertial versus noninertial models of attention. There was a main effect of distance, but more informatively, the distance $X$ sequence interaction indicated that the size of the sequence effect depended on the intercue distance. Stated equivalently, the change in RT as a function of intercue distance was different for first-cued and second- 
cued trials (Figure 3). For first-cued trials only, there was an effect of distance, but the post hoc comparisons indicated that no pair of distance conditions differed significantly. There was no systematic effect of distance condition on RT, which indicated that, on first-cued trials, attention was allocated in approximately the same manner across conditions.

In contrast to the lack of a clearly defined distance effect on first-cued trials, RTs on second-cued trials (Figure 3) had a peaked pattern with respect to distance, which suggests that some distance-dependent change in the allocation of attention occurred. Most inertial models of attention would predict an increase in RT with respect to distance, whereas noninertial models would predict constant RT as a function of distance; because the obtained pattern was inconsistent with both types of models, we examined it more closely. As was noted in the introduction, the Eriksen and Webb (1989) data also suggested nonmonotonic distance effects, but the effects were not significant statistically. However, these previous data had an RT peak that is similar to the present results.

Because we had no formal model in which to incorporate these unanticipated results, we examined some general models, formulated on the ordinal level, utilizing the concept of monotonicity. Monotonicity is an attribute of a function that is defined in the following manner: A function is monotonically increasing if, for every pair of points $\left(x_{1}, y_{1}\right)$ and $\left(x_{2}, y_{2}\right)$ such that $x_{2}>\mathrm{x}_{1}, y_{2} \geq y_{1}$. A monotonically decreasing function is defined in the same manner, except that $\leq$ is substituted for $\geq$; strictly monotonic functions are defined by substituting $>$ or $<$ for $<$ or $>$. In other words, a generally monotonic function may include sections that are flat (parallel to the $x$-axis), but a strictly monotonic function is always increasing (or decreasing).

As was stated previously, an inertial mechanism should produce a strictly monotonic increase of RT as a function of distance in the visual field, and a noninertial mechanism would be expected to produce flat RT-distance functions. Our results were not consistent with either type of mechanism; inspection of Figure 3 shows that the lowest mean RTs for second-cued trials occurred at both the shortest and the longest distances and that the two intermediate distances yielded the highest RTs. Therefore, we sought an alternative metric that would produce different condition orderings for the $x$-axis and, thus, rearrange conditions so as to yield a monotonic RT function.

Accordingly, we compared three models for the allocation of attention across the stimulus field, which are illustrated in Figure 4 . The first model, the distance model, corresponds to the straightforward movement of an attentional focus from the first-cued to the second-cued location. The second model, the area model, is based on limited-resource gradient or zoom lens models, in which the size of the attended area is inversely related to the strength of attention. According to the area model, at the onset of the first cue, the observer would allocate resources to the first-cued location and to possible second-cued location(s), and RT would be related to the total area enclosed. For the third model, the SST search model, on second-cued trials, the observer would conduct an SST search of possible target locations. Because the search would be terminated when the target was located, the mean number of second-cued locations searched would be 1.5 for the Distance 0,1 , and 2 conditions and 0.5 for the Distance 3 condition. The distance model was constructed

\section{Distance Model}

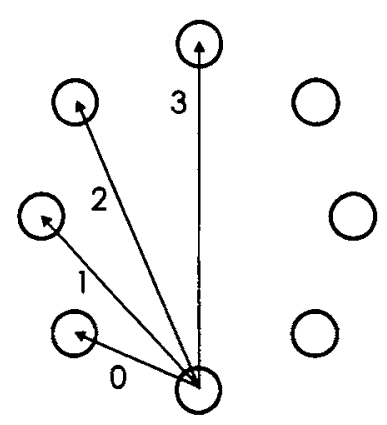

\section{Area and SST Models}

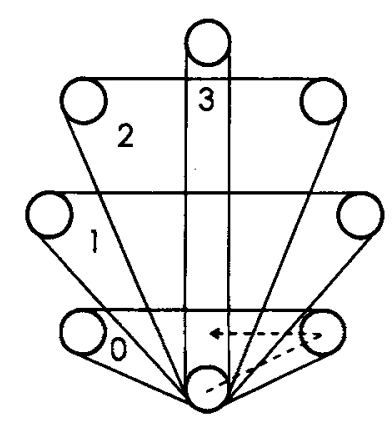

Figure 4. The metrics for second-cued reaction time examined in Experiment 1. Numbers on each figure correspond to the intercue distance condition. In the actual computation of distances and areas, all the possible starting points were considered. The left panel illustrates the metric according to the distance model, measured by linear distance between first- and second-cued locations. The right panel illustrates the metrics according to the area and serial selfterminating (SST) search models, which produced the same condition orderings. The area model metric is the area of the shape enclosing the first-cued and possible second-cued locations. The SST search metric is the mean search path distance of an SST mechanism (sample for Distance 0 condition is shown by dotted line). 

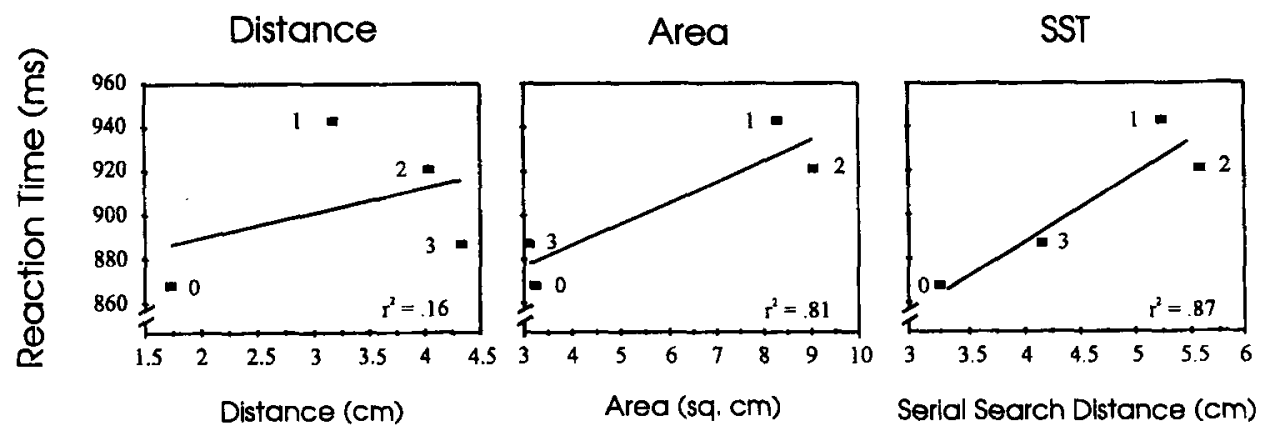

Figure 5. Mean second-cued reaction time on correct trials in Experiment 1 for each intercue distance $(0,1,2$, and 3), plotted against the distance (left), area (middle), and serial self-terminating (SST) search (right) metrics. Best linear regression fit is shown for each metric.

by measuring actual distance in centimeters, directly from the computer screen, between the first- and the secondcued positions. The areas and SST path lengths were also based on direct measurements from the computer screen (Figure 4). The measurements of distance, area, or SST path length were used to construct metrics for the three models; listing the intercue distance conditions in order of magnitude, for the distance model, the order was $0,1,2$, and 3 , whereas for the area and SST models, the order was $3,0,1$, and 2 , and $0,3,1$, and 2 , respectively.

Figure 5 illustrates RT as a function of the metrics for the models. The area model and the SST search model yielded similar condition orderings. The $r^{2}$ from linear regression was .16 for the distance model, .81 for the area model, and .87 for the SST search model (although linearity and monotonicity are distinct constructs). As is apparent in the figure, the distance model produces a greater violation of RT monotonicity than do the area and SST search models. We performed statistical tests of monotonicity for each model at the individual observer level, by computing Kendall's tau $(\tau)$, which is an ordering coefficient based on paired comparisons (Gonzalez \& Nelson, 1996; Kendall, 1970). According to each model, every pairwise comparison of points had a predicted direction of difference. For instance, under the distance model, Distance 1 RT should be lower than Distance 3 RT, whereas under the area/SST models, the reverse would hold. A pairwise comparison in the predicted direction is called concordant, and a pairwise comparison in the opposite of predicted direction is called discordant. Kendall's tau is computed by subtracting the number of discordant pairs from the number of concordant pairs and dividing by the total number of pairwise comparisons (six in our case). A strictly monotonic increasing trend would produce a score of 1 , and random trends would have a mean score of 0 .

On the individual observer level, the mean monotonicity scores were $.06, .29$, and .37 for the distance, area, and SST search models, respectively; for younger observers, the corresponding scores were $.12, .26$, and .41 ; for older observers, they were $0, .31$, and .33 . Wilcoxon matched-pairs signed-ranks tests on individual monoto- nicity scores indicated that the area and the SST search models did not differ from each other in fit, but they each provided higher scores of RT monotonicity than did the distance model $(p<.05)$; there were no significant differences across age groups. Therefore, we concluded that the area and SST search models provided better descriptions of the RT data than did the distance model. ${ }^{2}$ The area and SST search mechanisms were equivalent statistically and nonidentifiable mathematically (Townsend \& Ashby, 1983); therefore, the present discussion is agnostic with respect to the exact mechanism. The most important point is that both preferred models are inertial, but inertial with respect to a metric other than distance between first- and second-cued locations.

The results of Experiment 1 might also be accounted for by another type of mechanism: splitting of attention across noncontiguous locations in the display, with no attention being allocated to the region between possible target locations (Hahn \& Kramer, 1995; Kramer \& Hahn, 1995). The split-attention mechanism could account for the RT difference between first- and second-cued trials by assuming that more resources were allocated to the first-cued location than to the second-cued location(s), in part because (for distance conditions 0,1 , and 2) the probability of target appearance was higher at the firstcued location than at either of the second-cued locations taken individually (see, e.g., M. L. Shaw \& M. P. Shaw, 1977). The split-attention mechanism could also account for the relative RT advantage of Distances 0 and 3: Because attention would not have to be split in the Distance 0 condition and would be split across only two locations in the Distance 3 condition, second-cued RT might be faster in those conditions than in the Distance 1 and 2 conditions, in which it was presumably necessary to split attention across three noncontiguous locations. Note that the splitattention explanation is not radically different from the area model, in that both mechanisms posit flexibility in the allocation of resources and relate performance to the physical parameters of the attended area(s). The main distinction between the two models is that, in the area model, RT would be related to the area of the attended locations, whereas in the split-attention mechanism, RT 
would be presumably related to both the number of distinct locations to be attended and the area(s) of those locations. In the present paradigm, the two models cannot be differentiated.

Another possibility is that the nonmonotonic RT patterns of second-cued trials were due to effects of visual hemifield, as defined by the vertical line passing through fixation. The proportions of trials in which the first and second cues were in different hemifields were $.25, .50$, .75 , and .75 in the Distance $0,1,2$, and 3 conditions, respectively. An ANOVA, with hemifield crossing as a factor, indicated that there was a main effect of hemifield crossing $[F(1,62)=45.57, p<.001]$, with differenthemifield trials $(M=849 \mathrm{msec})$ being faster than samehemifield trials $(M=877 \mathrm{msec})$. There was also an interaction of hemifield crossing $X$ sequence $X$ distance $[F(3,186)=12.45, p<.001]$. There were no significant interactions involving age group. This finding of lower RTs for different-hemifield trials than for same-hemifield trials is inconsistent with the findings of Egly and Homa (1991) and Henderson and Macquistan (1993), who failed to find costs or benefits of crossing a meridian. Statistical investigation of the RT-distance plots for each combination of hemifield crossing and sequence indicated that the nonmonotonic pattern was preserved even after segregating trials by hemifield crossing, which eliminated hemifield effects as an explanation. The finding that different-hemifield trials were faster than same-hemifield trials may warrant future investigation, but it does not explain the nonmonotonicities in second-cued RT.

Comparison with Eriksen and Webb (1989). The present results are consistent with those of Eriksen and Webb (1989, Experiment 2), which are reproduced in Figure 1. Eriksen and Webb, whose first cue preceded the target display by $50 \mathrm{msec}$, found a $60-\mathrm{msec}$ cuing effect, with first-cued trials being faster than second-cued trials; this was comparable to our sequence effect. Unlike the present results, however, they found no sequence $x$ distance interaction for RT, leading them to conclude that there were no distance effects or area metrics. As was stated in the introduction, the patterns of RTs and errors that Eriksen and Webb found, although not significant statistically, indicated some possible nonmonotonicities with respect to distance; these patterns were similar to the pattern of errors and RTs in the present data (Figure 3 ). In contrast to error rates that ranged between $6 \%$ and $19 \%$ in the Eriksen and Webb results, the error rate range in the present results was considerably lower $(<5 \%$ for each age group). The reduction in error rate was most probably due to the longer target/distractor display durations (150 msec for Eriksen \& Webb vs. $745 \mathrm{msec}$ in the present experiment). Also, the present observers may have placed less emphasis on response speed (mean RT for younger adults in Experiment 1 was approximately 100 msec higher than that in Eriksen \& Webb), which may have reduced the error rates.

Conclusion. In summary, Experiment 1 provided evidence that observers (both younger and older) allocated attention in an inertial manner, as inferred from the RT functions that were nonmonotonic with intercue distance but were more monotonic with alternative metrics. These preferred metrics corresponded to either gradient or SST spotlight models, in which, respectively, the area of the relevant region of the visual field or the mean path length determined RT to the second-cued target. These results replicated the pattern of effects from Eriksen and Webb (1989), but in contrast to their failure to find significant distance effects, which they interpreted as evidence of the noninertial effects of attention, we did obtain statistically significant effects, from which we inferred an inertial gradient or SST search model. These inertial effects indicate that multi-item displays somehow interfere with the serial noninertial allocation of attention, which was found for displays not containing distractors (Kwak et al., 1991; Madden, 1990; Madden et al., 1994; Remington \& Pierce, 1984; Sagi \& Julesz, 1985). When the display does not contain distractors, any preattentional information (i.e., bottom-up activation from the display) will indicate the target location with almost $100 \%$ probability. In contrast, in a cluttered display, there is bottom-up information coming from many locations, and the focus of attention may be delayed in its transit to the target location by activation from nontargets. Another possibility is that, in the presence of distractors, the visual system may reduce its reliance on preattentional guidance and engage in a more deliberate search for the target. Therefore, it appears that the mode of attention that is used in a distractorfilled display is different from that used when the display contains only a target.

Although there was an age group main effect, with older adult RT being higher than younger adult RT, performance in most respects was similar across age groups. Most notably, the two age groups were similar in the pattern of second-cued RTs across distance, which indicated that younger and older observers were allocating attention in the same manner. Both age groups showed inertial effects corresponding to either the area or the mean path length of the set of possible target locations in each condition, as was stated previously.

The single interaction involving age group was found in the larger sequence effect (second- minus first-cued RT) for younger adults than for older adults. This result indicated that younger adults most likely allocated more attention in response to the first cue than did older adults. Given that the primary finding (age group similarity of allocation over intercue distance) contradicts predictions of general slowing, Experiment 1 must be added to the growing set of studies that have found preservation of visual selective attention in older adults (e.g., Folk \& Hoyer, 1992; Gottlob \& Madden, 1998; Greenwood \& Parasuraman, 1994; Greenwood et al., 1993; Hahn \& Kramer, 1995; Madden, 1990; Madden et al., 1994).

Because different distances were presented in separate blocks, it was possible for observers to adopt a particular attentional set for each block, in order to optimize performance. One way to test this possibility is to replicate 
the experiment, but with distances mixed within single blocks. Therefore, Experiment 2 was conducted according to the reasoning that, if the pattern of data in Experiment 1 was due to adopting different sets for each intercue distance, then when intercue distance is randomized within blocks, the pattern would not be preserved. If the nonmonotonic RTs were due to a single set across all blocks, the pattern of data would be preserved in mixed blocks (Possamaï \& Bonnel, 1991).

\section{EXPERIMENT 2}

\section{Method}

Observers. Twenty-four younger adults (18-30 years of age) and 24 older adults (61-75 years of age), from the same subject populations as those in Experiment 1, participated. There was an equal number of men and women in each group. The younger observers participated for course credit, and the older observers were paid for their participation. The same tests as those in Experiment 1 (WAIS-R Digit Symbol and Vocabulary, and corrected near visual acuity) were administered to all the observers. Observer characteristics are listed in Table 1.

Apparatus, Stimuli, and Procedure. Only one modification was made to the procedure in Experiment 1 (Figure 2). The same trials were used, including within-subjects variables of target type, target location, directional relationship between first-cued and second-cued locations, and cue sequence. However, the four intercue distances were not presented in separate trial blocks but, instead, were pseudorandomized within blocks. Within each block, target type (two levels), sequence (two levels), and distance (four levels) were crossed, yielding 4 trials of each combination of those variables per 64-trial block. Directional relationship between first- and second-cued locations and target location was pseudorandomized over all experimental trials, controlling for runs of greater than three on any variable. There were six blocks consisting of 64 experimental trials, plus one block of 64 practice trials at the beginning of the session. The between-subjects variables of response-to-key assignment (two levels) and block order (four levels) were counterbalanced as in Experiment 1, so that 3 observers (at least 1 of each gender) in each age group were assigned to each combination of variables.

\section{Results}

Mean reaction time. Mean RT for correct responses, as a function of sequence and distance, are presented in Figure 6 for both age groups. A repeated measures ANOVA on RT was performed as in Experiment 1, with age group as a between-subjects variable and distance $(0$, 1,2 , or 3 ) and sequence (first-cued or second-cued) as within-subjects variables. The alpha level for all tests was set at .05 . Power analyses indicated that, at alpha $=$ .05 , there was a greater than .80 power to detect an effect size $(f)$ of .42 for main effects of age group and sequence and for the age group $\times$ sequence interaction. There was also a greater than .80 power to detect an $f$ of .29 for the main effect of distance and for all the interactions involving distance.

The age group main effect $\left[F(1,46)=36.79, M S_{\mathrm{e}}=\right.$ $152,709]$ represented a higher mean RT for older adults $(992 \mathrm{msec})$ than for younger adults $(750 \mathrm{msec})$. The main effect of distance $\left[F(3,138)=7.68, M S_{\mathrm{e}}=2,605\right]$ represented a decrease in RT as a function of intercue distance. Sidak paired comparisons indicated that mean RT for adjacent distances (i.e., Distances 0 vs. 1,1 vs. 2 , and 2 vs. 3 ) did not differ, but that all distances that were not adjacent differed in mean RT (minimum difference $=20 \mathrm{msec}$ ).

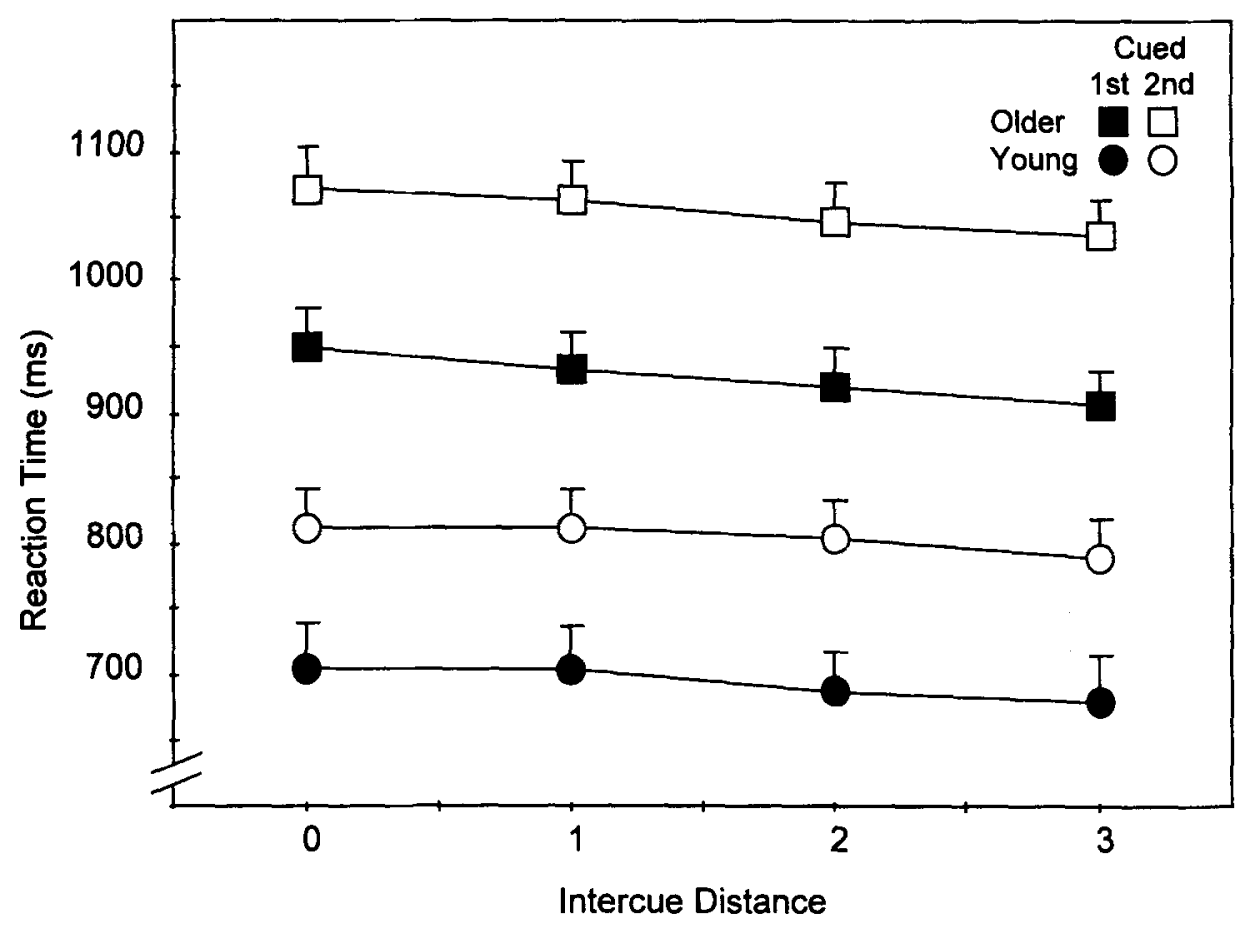

Figure 6. Mean reaction times on correct trials as a function of first- versus second-cued trial for Experiment 2, for the two age groups. 
Table 2

Error Rates

\begin{tabular}{|c|c|c|c|c|c|c|c|c|}
\hline \multirow[b]{3}{*}{ Distance } & \multicolumn{4}{|c|}{ Young Observers } & \multicolumn{4}{|c|}{ Older Observers } \\
\hline & \multicolumn{2}{|c|}{ First-Cued } & \multicolumn{2}{|c|}{ Second-Cued } & \multicolumn{2}{|c|}{ First-Cued } & \multicolumn{2}{|c|}{ Second-Cue } \\
\hline & $M$ & $\overrightarrow{S D}$ & $M$ & $S D$ & $M$ & $S D$ & $M$ & $S D$ \\
\hline \multicolumn{9}{|c|}{ Experiment 1} \\
\hline 0 & 1.7 & 2.5 & 3.4 & 4.2 & 2.5 & 3.1 & 4.0 & 4.9 \\
\hline 1 & 1.4 & 2.2 & & 4. & & 4.7 & 7.8 & 6.7 \\
\hline 2 & 1. & 1.9 & 4.2 & 4.3 & 3.9 & 6.0 & 6.8 & 5.3 \\
\hline 3 & 1.8 & 2.4 & 4.8 & 5.0 & 3.5 & 4.0 & 3.8 & 4.5 \\
\hline \multicolumn{9}{|c|}{ Experiment 2} \\
\hline 0 & 2.5 & 2.2 & $5.1^{\circ}$ & 4.1 & 4.5 & 5,1 & 6.4 & 4.0 \\
\hline 1 & 0.9 & 1.1 & 4.3 & 3.5 & 2.9 & 2.3 & 6.5 & 3.2 \\
\hline 2 & 1.0 & 1.5 & 3.7 & 3.3 & 3.0 & 2.9 & 4.8 & 2.4 \\
\hline 3 & 0.7 & 1.2 & 3.9 & 3.7 & 2.8 & 3.3 & 4.3 & 2.5 \\
\hline
\end{tabular}

Note-Values are percentages.

Preplanned simple-effects tests of distance at each combination of age group and sequence indicated a distance effect for older adults in the first-cued condition $\left[F(3,69)=4.09, M S_{\mathrm{e}}=2,151\right]$, although they were suggestive $(p<.06)$ for two other cases: younger adults' first-cued trials and older adults' second-cued trials. The main effect for sequence $\left[F(1,46)=110.70, M S_{\mathrm{e}}=\right.$ $12,287]$ represented a lower mean RT for first-cued targets $(811 \mathrm{msec})$ than for second-cued targets $(930 \mathrm{msec})$. There were no significant interactions. A Brinley plot comparing older and younger RTs yielded the following best-fit linear regression line: $\mathrm{RT}_{\text {older }}=138 \mathrm{msec}+$ $1.14\left(\mathrm{RT}_{\text {younger }}\right) ; r^{2}=.99$. The error rates (Table 2 ) were low $(2.8 \%$ for younger adults and $4.4 \%$ for older adults) and did not indicate any speed-accuracy tradeoffs.

Comparison of Experiments 1 and 2. In order to compare the results with those of Experiment 1, an ANOVA with the added variable of experiment (1 vs. 2) was performed on RT; main effects and interactions involving the experiment variable will be summarized here. There was no main effect of experiment, indicating that overall performance level was not affected by the trial-mixing manipulation. However, there were several interactions involving experiment. The experiment $\times$ distance $\times$ sequence interaction was significant $[F(3,324)=$ $\left.10.87, M S_{\mathrm{e}}=1,170\right]$, because the distance $\times$ sequence interaction was significant in Experiment 1 but not in Experiment 2 . As a follow-up to the three-way interaction, the experiment $x$ distance interaction was examined at each level of sequence. This interaction was significant for first- and second-cued trials $\left[F(3,324)=4.63, M S_{\mathrm{e}}=\right.$ 2,404 , and $F(3,324)=13.47, M S_{\mathrm{e}}=2,571$, respectively], indicating that the distance functions had different shapes across experiment. In an equivalent analysis, the experiment $\times$ sequence interaction was examined at each level of distance. For Distances 0 and 3 , the interactions were significant $\left[F(1,110)=14.97, M S_{\mathrm{e}}=2,879\right.$, and $F(1,110)=12.32, M S_{\mathrm{e}}=2,962$, respectively]. These interactions represented increases in the sequence effect (Experiment 2 - Experiment 1 ) of 56 and $52 \mathrm{msec}$, re- spectively, for Distances 0 and 3. For Distances 1 and 2, the sequence effects changed by $-1 \mathrm{msec}$, and these interactions were not significant.

\section{Discussion}

Age effects. As was reported above, the mean RT was again higher for older adults than for younger adults, this time by $242 \mathrm{msec}$, which is very similar to the $238-\mathrm{msec}$ difference in Experiment 1. However, in the present results, there were no age-related interactions, indicating that the size of the cuing effect and the pattern of attention allocation were similar across age groups. This similarity in performance was confirmed by the Brinley plot slope of 1.1, which is close to a slope of 1 , indicating an equivalence of task condition effects for the two groups. In summary, once the overall speed of responding was accounted for, it appeared that observers of both age groups allocated attention in a similar fashion, as we found in Experiment 1.

Sequence and distance effects. As in Experiment 1, targets at first-cued locations were identified more quickly than targets at second-cued locations, which indicated again that the cue facilitated the allocation of attention. One particularly interesting distance effect is the decrease in RT as a function of distance on first-cued trials, which was significant for older observers and suggestive for younger observers. On any given trial in Experiment 2, distance was (pseudo)randomly determined; therefore, the only difference across distance conditions on firstcued trials was the location of the second cue (adjacent to a distractor). The decline in RT with intercue distance indicated that the proximity of the second cue was proportional to the amount of interference (small but significant). Therefore, we conclude that the focus of attention subtended an area larger than a single target location or that the second cue was detected and caused response interference in some trials.

In addition, the distance-mixing manipulation in Experiment 2 affected the distance function on second-cued trials. In Experiment 1, the second-cued distance function was nonmonotonic, which we interpreted as evidence for gradient or SST search models. In contrast, however, the second-cued distance function in Experiment 2 was slightly decreasing, although only for older adults (at $p<$ .06; Figure 6). This distance function more closely resembles the results of Eriksen and Webb (1989) than does the function from Experiment 1, which suggests that the observers in both age groups were capable of allocating attention to the entire relevant display.

In Experiment 1, we observed that the results would be consistent with either a flexible gradient or an SST search mechanism. As in Experiment 1, we assume that the observers employed a strategy with the goal of maximizing the probability of correctly identifying the target, but in Experiment 2, the observers were faced with the additional uncertainty of the location of the secondcued target. In Experiment 1, there were only one or two possible second-cued target locations on each trial, once 
the first-cued location was determined. In contrast, in Experiment 2, there were seven possible second-cued target locations on every trial. This extra location uncertainty may have imposed an additional load, as compared with the conditions in Experiment 1 . The experiment $\times$ sequence interactions for Distance 0 and 3 trials indicated that the extra location uncertainty in Experiment 2 may have interfered with second-cued target processing, as compared with Experiment 1, in which the second-cued target location was more predictable.

In terms of the area model, the results of Experiment 2 would not be compatible either with a single distribution of attention covering all eight locations evenly or with a gradient originating at the first-cued location and tapering off as a function of distance. Possible modes of allocation would be either a single, concentrated spotlight of attention at the first-cued location, coupled with a diffuse gradient covering the other seven locations (LaBerge, Carlson, Williams, \& Bunney, 1997), or a quick succession of focused and diffuse processing.

The RT orderings may also be explained in the context of an SST search mechanism, albeit with more difficulty. Whereas Eriksen and Webb (1989) concluded that their results most likely implicated a serial noninertial search of second-cued locations, we infer, on the basis of the results of Experiment 1, that a serial search has inertial properties in this paradigm. It may be the case that the inertial properties of attention are most pronounced when search is confined to a single intercue distance.

As was mentioned previously, however, there is a suggestion that second-cued RT slightly declines with distance (at least for older adults). A possible SST search strategy would be to orient to the first-cued location first and, if necessary, to search the diametrically opposite (Distance 3) location next. Then the other locations would be searched systematically. If the search were conducted using a strictly clockwise or counterclockwise path, a specific prediction regarding RT variance could be made: Lower variances should be observed at Distance 3 and 0 locations than at the other two distance locations. The reasoning is as follows, with reference to Figure 4: If the locations are ranked according to search order in both clockwise and counterclockwise directions, starting at the Distance 3 location and skipping the first-cued location, the possible ranks for the Distance 3 location will be $(1,1)$, for the Distance 2 location $(2,7)$, for the Distance 1 location $(3,6)$, and for the Distance 0 location $(4,5)$. Regardless of whether observers employ a directional bias (clockwise vs. counterclockwise) or choose directions randomly, RT should have the lowest variance at Distances 3 and 0 . In order to investigate the SST search predictions for RT variance, we computed RT standard deviations on the individual observer level: The mean second-cued RT SDs were 199, 194, 194, and 187 for Distances $0,1,2$, and 3 , respectively, and there were no significant pairwise differences across distance conditions $(p>.5)$. Thus, it appeared that the observers were not using an SST search mechanism that performed a strict search in a circular path. Of course, the observers may have employed other SST search strategies, including those of searching in a zigzag pattern or searching with guidance from preattentional information on target location. The split-attention model (Kramer \& Hahn, 1995), as was mentioned in the discussion of Experiment 1, would not be applicable to the results of Experiment 2, because of the larger number of possible second-cued locations on every trial.

Comparison of Experiments 1 and 2. Mean RT for first-cued trials was $811 \mathrm{msec}$, which was identical to mean RT for first-cued trials in Experiment 1. Error rates on first-cued trials were also comparable $(2.6 \%$ for Experiment 1 and $2.3 \%$ for Experiment 2). This similarity in performance across experiments (using different observers) suggests that the change from blocked to mixed distances did not affect overall preparation for targets appearing at the first-cued location. In contrast, mean RT for second-cued trials went from $905 \mathrm{msec}$ in Experiment 1 to $930 \mathrm{msec}$ in Experiment 2, although the difference was not significant $\left[F(1,108)=1.11, M S_{\mathrm{e}}=\right.$ $63,252]$. For Distance 1 and 2 targets, the sequence effect did not change between Experiment $1(M=122 \mathrm{msec})$ and Experiment $2(M=121 \mathrm{msec})$. For Distance 0 and 3 targets, however, the sequence effect in Experiment 2 $(M=120 \mathrm{msec})$ was larger in magnitude than the sequence effect in Experiment $1(M=66 \mathrm{msec})$, as is demonstrated by the experiment $\times$ sequence interactions for those two distances. It appears that the added uncertainty about the location of the target on second-cued trials, owing to mixing the distances, made the shift of attention between the first-cued and the second-cued display locations more difficult for the closest and the most remote distances. Equivalently, the attentional sets employed in Experiment 1 improved second-cued performance at Distances 0 and 3. Because both area and SST distance are smallest for the Distance 0 and 3 conditions (Figure 5), these conditions benefit most from the concentration or restriction of attention when that is required. In contrast, the attentional states for Distances 1 and 2 did not seem to differ between the two experiments.

Conclusion. The results of Experiment 2 indicated that the peaked distance functions of second-cued trials in Experiment 1 were most likely due to the observers adopting specific attentional sets corresponding to intercue distance, because these functions were no longer peaked when the distance conditions were presented in mixed blocks. The changes across experiments were primarily confined to the increases in sequence effect at the Distance 0 and Distance 3 locations, which indicated that attention had been concentrated in these conditions in Experiment 1. An additional, unanticipated result was that RT decreased slightly as a function of distance in Experiment 2. Decreasing functions would be inconsistent with canonical versions of area and/or SST search models, but consistent with variants of these models. Again, as in Ex- 
periment 1 , a noninertial model of attentional allocation was falsified, and again, we found no evidence of agerelated slowing in the allocation of visual attention.

In both Experiment 1 and Experiment 2, the RT-distance functions indicated that larger intercue distances did not impair the movement of attention, relative to shorter intercue distances. One explanation that we needed to consider was that the unusual RT-distance functions were due to eye movements. As was stated in the introduction, there is evidence that saccadic eye movements are noninertial (Clark \& Stark, 1975), so it is possible that the observers were producing relatively short RTs to Distance 3 targets by executing a saccade to the second-cued target location. In some respects, the data from Experiments 1 and 2 produced evidence to the contrary: If the observers foveated the center of the display, all targets would appear at the same retinal eccentricity, as was explained previously. However, if the first-cued target location were foveated, on second-cued trials, intercue distance and retinal eccentricity would coincide, which would tend to produce monotonically increasing RT-distance functions, owing to the decreased detectability of targets and cues at the periphery, especially in Experiment 2 where second-cued target locations were equiprobable. Still, the possibility remained that the observers employed some sort of strategy, such as fixating the center of the display and executing a saccade only on second-cued trials, with a greater propensity to saccade to locations opposite the first-cued location. This strategy, in particular, could have accounted for the nonmonotonicities observed in Experiment 1.

In order to investigate the eye-movement hypothesis, we replicated Experiment 1 with 17 young observers, using shorter duration (373-msec) target displays. Head and eye movements were prevented by using a fixed chinrest and by monitoring with closed-circuit TV. Although error rate $(11 \%)$ was higher than that for Experiment 1 (presumably owing to the decreased target duration), the pattern of RTs was almost identical to that of Experiment 1 . Statistical tests showed no interactions involving experiment. Our conclusion, therefore, was that the results of Experiment 1 were not due to eye movements.

\section{GENERAL DISCUSSION}

Our main goal in the present set of experiments was to investigate age-related changes in the dynamic attributes of visual selective attention. Specifically, we wanted to investigate whether the space-based properties of attention were inertial or noninertial in a display with distractors present and whether these properties differed across age groups. We found inertial effects (Experiment 1) for observers in both age groups, consistent with either a gradient or an SST search mechanism. These inertial properties contrast with previous findings of noninertial effects in both distractor-absent displays (Madden, 1990; Madden et al., 1994) and the distractor-present display of Eriksen and Webb (1989), whose RT data we replicated in most respects.

In both experiments, RT and error rate were lower on first-cued trials than on second-cued trials. Even though both cues had $50 \%$ validity, there were two ways in which perceptual salience was greater for the first cue than for the second cue: (1) The first cue preceded the display by $115 \mathrm{msec}$, whereas the second cue was concurrent with the display; and (2) the first cue was presented as a sole, abrupt-onset item, whereas the second cue was one of nine items appearing simultaneously. It has been shown that abrupt-onset items draw attention relatively effortlessly (Remington, Johnston, \& Yantis, 1992; but see Yantis \& Jonides, 1990) and are associated with a rapid $(<100 \mathrm{msec})$ and transient allocation of attention (e.g., Cheal \& Lyon, 1991; Nakayama \& Mackeben, 1989). Therefore, it is possible that attentional allocation to first-cued targets was relatively automatic and that allocation to second-cued targets was more effortful and less automatic.

The distance effects in Experiment 1 indicated that the movement of attention was inertial, although RT did not increase monotonically as a function of intercue distance, as would be expected if attention were shifted from the first-cued location directly to the second-cued location with a finite speed. In Experiment 1, in which intercue distance was varied across blocks, second-cued RT was consistent with either an area or an SST search model, according to which the observers adopted a particular attentional set that took into account possible second-cued target locations. In Experiment 2, in which distances were mixed and all locations other than the first-cued location were possible second-cued locations, it appeared that the observers adopted a single attentional set producing a slightly decreasing distance function, which we described in terms of an area model or an SST search model.

When we compared Experiments 1 and 2, we found that the major differences across experiments lay in the sequence effects. In Experiment 1, in which the observers could adopt specific attentional preparations according to intercue distance, the sequence effect for Distances 0 and 3 was relatively small $(M=66 \mathrm{msec})$; in Experiment 2, this effect increased by $54 \mathrm{msec}$. The sequence effect for Distances 1 and 2, however, did not change across experiments $(M=121 \mathrm{msec})$. The implication of this pattern is that attention could be effectively confined to the two smaller regions in Experiment 1, whereas attention to the larger regions (Distances 1 and 2) in Experiment 1 was similar to the attentional distribution covering all eight locations in Experiment 2.

In general, age group comparisons were consistent with the preservation of attentional function. One interesting age group difference was the age $\times$ sequence interaction on RT in Experiment 1, indicating that the sequence effect was greater for younger adults $(108 \mathrm{msec})$ than for older adults $(80 \mathrm{msec})$, from which we inferred that younger adults were allocating more attention to the first-cued location. 
The results are consistent with previous research indicating that younger adults have a more pronounced response to abrupt-onset cues at short cue- target intervals than do older adults (S. S. Steinman et al., 1994). However, they are not consistent with a generalized slowing theory, which, on the basis of the 238-msec difference in mean RT (older RT > younger RT), would predict a greater sequence effect for older adults than for younger adults.

Although we did find an age group difference in the size of the cuing effect in Experiment 1, more relevant were the similarities in the intercue distance effects across age groups, both in Experiment 1, in which distances were presented in separate blocks, and in Experiment 2, in which distances were mixed within blocks. There were no RT interactions involving both age and distance in either of the experiments, which indicates that the allocations or movements of attention were essentially comparable across age groups. According to the evidence in Experiment 1, both age groups were effective in allocating attention primarily to the subset of locations in the display that were likely to contain targets, either by spreading attention to cover the relevant locations or by conducting SST searches that were restricted to the relevant locations. According to a theory of generalized age-related slowing, older adults would be expected to manifest a more restricted distribution or a slower movement of attention, but as can be seen in Figures 3 and 6, RT as a function of intercue distance has a similar pattern for the two age groups. The Brinley plots confirm these observations: The plot for Experiment 1 had a slope of less than 1, and the plot for Experiment 2 had a slope of approximately 1 (1.1), which indicated that older adults were comparable with younger adults in the attentional processes. In the present task, older adults were at least as efficient as younger adults in allocating or moving attention across possible target locations in multi-item displays.

\section{REFERENCES}

BrinLEY, J. F. (1965). Cognitive sets, speed and accuracy of performance in the elderly. In A. T. Welford \& J. E. Birren (Eds.), Behavior, aging, and the nervous system (pp. 114-149). Springfield, IL: Thomas.

CAstiello, U., \& Umiltà, C. (1992). Splitting focal attention. Journal of Experimental Psychology: Human Perception \& Performance, 18 , 837-848

Cerella, J. (1985). Information processing rates in the elderly. Psychological Bulletin, 98, 67-83.

Cheal, M. L., \& LYON, D. R. (1991). Importance of precue location in directing attention. Acta Psychologica, 76, 201-211.

Clark, M. R., \& STARK, L. (1975). Time optimal behavior of human saccadic eye movement. IEEE Transactions on Automatic Control, AC-20, 345-348.

COHEN, J. (1988). Statistical power analysis for the behavioral sciences. Hillsdale, NJ: Erlbaum.

COOPER, L. A. (1976). Demonstration of a mental analog of an external rotation. Perception \& Psychophysics, 19, 296-302.

DuNCAN, J. (1980). The demonstration of capacity limitation. Cognitive Psychology, 12, 75-96.

DunCAN, J. (1984). Selective attention and the organization of yisual information. Journal of Experimental Psychology: General, 113, 501517.
Egeth, H., \& Dagenbach, D. (1991). Parallel versus serial processing in visual search: Further evidence from subadditive effects of visual quality. Journal of Experimental Psychology: Human Perception \& Performance, 17, 551-560.

EGLY, R., \& HoMA, D. (1991). Reallocation of visual attention. Journal of Experimental Psychology: Human Perception \& Performance, 17, 142-159.

ERIKSEN, C. W. (1990). Attentional search of the visual field. In D. Brogan (Ed.), Visual search (pp. 3-19). London: Taylor \& Francis.

Eriksen, C. W., \& Murphy, T. D. (1987). Movement of attentional focus across the visual field: A critical look at the evidence. Perception \& Psychophysics, 42, 299-305.

ERIKSEN, C. W., \& ST. J AMES, J. D. (1986). Visual attention within and around the field of focal attention: A zoom lens model. Perception \& Psychophysics, 40, 225-240.

ERIKSEN, C. W., \& WEBB, J. M. (1989). Shifting of attentional focus within and about a visual display. Perception \& Psychophysics, 45, 175-183.

ERIKSEN, C. W., \& YeH, Y. Y. (1985). Allocation of attention in the visual field. Journal of Experimental Psychology: Human Perception \& Performance, 11, 583-597.

FolK, C. L., \& HOYER, W. J. (1992). Aging and shifts of visual spatial attention. Psychology \& Aging, 7, 453-465.

Games, P. A. (1977). An improved $t$ table for simultaneous control on $\mathrm{g}$ contrasts. Journal of the American Statistical Association, 72, 359.

GonZalez, R., \& NELSON, T. O. (1996). Measuring ordinal associations in situations that contain tied scores. Psychological Bulletin, 119 , 159-165.

GoTTLOB, L. R., \& MADDEN, D. J. (1998). Time course of attentional allocation after equating for sensory differences: An age-related perspective. Psychology \& Aging, 13, 138-149.

Grady, C. L., McIntosh, A. R., Horwitz, B., Maisog, J. M., Ungerleider, L. G., Mentis, M. J., Pietrini, P., Schapiro, M. B., \& HAXBY, J. V. (1995). Age-related reductions in human recognition memory due to impaired encoding. Science, 269, 218-221.

Greenwood, P. M., \& Parasuraman, R. (1994). Attentional engagement deficit in nondemented elderly over 75 years of age. Aging \& Cognition, 1, 188-202.

Greenwood, P. M., Parasuraman, R., \& Haxby, J. (1993). Changes in visuospatial attention over the adult lifespan. Neuropsychologia, 31, 471-485.

HahN, S., \& Kramer, A. F. (1995). Attentional flexibility and aging: You don't need to be 20 years of age to split the beam. Psychology \& Aging, 10, 597-609.

Handy, T. C., Kingstone, A., \& Mangun, G. R. (1996). Spatial distribution of visual attention: Perceptual sensitivity and response latency. Perception \& Psychophysics, 58, 613-627.

Hartley, A. A. (1992). Attention. In F. I. M. Craik \& T. A. Salthouse (Eds.), The handbook of aging and cognition (pp. 3-50). Hillsdale, NJ: Erlbaum.

Hartley, A. A., Kieley, J. M., \& Slabach, E. H. (1990). Age differences and similarities in the effects of cues and prompts. Journal of Experimental Psychology: Human Perception \& Performance, 16, 523-537.

Henderson, J. M. (1991). Stimulus discrimination following covert attentional orienting to an exogenous cue. Journal of Experimental Psychology: Human Perception \& Performance, 17, 91-106.

HENDERSON, J. M. (1996). Spatial precues affect target discrimination in the absence of visual noise. Journal of Experimental Psychology: Human Perception \& Performance, 22, 780-787.

Henderson, J. M., \& MacQuistan, A. D. (1993). The spatial distribution of attention following an exogenous cue. Perception \& Psychophysics, 53, 221-230.

KENDALL, M. G. (1970). Rank correlation methods (4th ed.). London: Charles Griffin.

Kramer, A. F., \& HahN, S. (1995). Splitting the beam: Distribution of attention over noncontiguous regions of the visual field. Psychological Science, 6, 381-386.

Kwak, H.-W., Dagenbach, D., \& EgEth, H. (1991). Further evidence 
for a time-independent shift of the focus of attention. Perception \& Psychophysics, 49, 473-480.

LABERGE, D., \& BROWN, V. (1989). Theory of attentional operations in shape identification. Psychological Review, 96, 101-124.

LaBerge, D., Brown, V., Carter, M., Bash, D., \& Hartley, A. (1991). Reducing the effects of adjacent distractors by narrowing attention. Journal of Experimental Psychology: Human Perception \& Performance, 17, 65-76.

Laberge, D., Carlson, R. L., Williams, J. K., \& Bunney, B. G. (1997). Shifting attention in visual space: Tests of moving-spotlight models versus an activity-distribution model. Journal of Experimental Psychology: Human Perception \& Performance, 23, 1380-1392.

Luck, S. J., Hillyard, S. A., Mouloua, M., \& Hawkins, H. L. (1996). Mechanisms of visual-spatial attention: Resource allocation or uncertainty reduction? Journal of Experimental Psychology: Human Perception \& Performance, 22, 725-737.

MADDEN, D. J. (1984). Data-driven and memory-driven selective attention in visual search. Journal of Gerontology, 39, 72-78.

MADDEN, D. J. (1985). Adult age differences in memory-driven selective attention. Developmental Psychology, 21, 655-665.

MADDEN, D. J. (1986). Adult age differences in the attentional capacity demands of visual search. Cognitive Development, 1, 335-363.

MADDEN, D. J. (1990). Adult age differences in the time course of visual attention. Journal of Gerontology: Psychological Sciences, 45, P9-P16.

MADDEN, D. J. (1992). Selective attention and visual search: Revision of an allocation model and application to age differences. Journal of Experimental Psychology: Human Perception \& Performance, 18, 821-836

Madden, D. J., Connelly, S. L., \& Pierce, T. W. (1994). Adult age differences in shifting focused attention. Psychology \& Aging, 9, 528-538.

Madden, D. J., \& Gottlob, L. R. (1997). Adult age differences in strategic and dynamic components of focusing visual attention. $\mathrm{Ag}$ ing, Neuropsychology, \& Cognition, 4, 185-210.

MADDEN, D. J., \& PLUDE, D. J. (1993). Selective preservation of selective attention. In J. Cerella, J. Rybash, W. Hoyer, \& M. L. Commons (Eds.), Adult information processing: Limits on loss (pp. 273-300). San Diego: Academic Press.

Madden, D. J., Turkington, T. G., Provenzale, J. M., Hawk, T. C., HOFFMAN, J. M., \& COLEMAN, R. E. (1997). Selective and divided visual attention: Age-related changes in regional cerebral blood flow measured by $\mathrm{H}_{2}^{15} \mathrm{O}$ PET. Human Brain Mapping, 5, 389-409.

Myerson, J., Hale, S., Wagstaff, D., Poon, L., \& Smith, G. A. (1990). The information loss model: A mathematical theory of agerelated cognitive slowing. Psychological Review, 97, 475-487.

Nakayama, K., \& Mackeben, M. (1989). Sustained and transient components of focal visual attention. Vision Research, 29, 1631-1647.

Possamaï, C.-A., \& BonNeL, A.-M. (1991). Early modulation of visual input: Constant versus varied cuing. Bulletin of the Psychonomic Society, 29, 323-326.

RaFAL, R., \& RoberTSON, L. (1995). The neurology of visual attention. In M. S. Gazzaniga (Ed.), The cognitive neurosciences (pp. 625-648). Cambridge, MA: MIT Press.

Raz, N., Gunning, F. M., Head, D., Dupuis, J. H., McQuain, J., BrigGs, S. D., LOKEN, W. J., THORNTON, A. E., \& ACKER, J. D. (1997). Selective aging of the human cerebral cortex observed in vivo: Differential vulnerability of the prefrontal gray matter. Cerebral Cortex, 7, 268-282.

REMINGTON, R. W., Johnston, J. C., \& YANTIS, S. (1992). Involuntary attentional capture by abrupt onsets. Perception \& Psychophysics, 51, 279-290.

Remington, R. [W.], \& Pierce, L. (1984). Moving attention: Evidence for time-invariant shifts of visual selective attention. Perception \& Psychophysics, 35, 393-399.
SAGI, D., \& JULESZ, B. (1985). Fast noninertial shifts of attention. Spatial Vision, 1, 141-149.

SALThOUSE, T. A. (1996). The processing-speed theory of adult age differences in cognition. Psychological Review, 103, 403-428.

Salthouse, T. A., Fristoe, N. M., Lineweaver, T. T., \& COON, V. E. (1995). Aging of attention: Does the ability to divide decline? Memory \& Cognition, 23, 59-71.

Salthouse, T. A., Rogan, J. D., \& Prill, K. A. (1984). Division of attention: Age differences on a visually presented memory task. Memory \& Cognition, 12, 613-620.

SHAW, M. L., \& SHAW, M. P. (1977). Optimal allocation of cognitive resources to spatial locations. Journal of Experimental Psychology: Human Perception \& Performance, 3, 201-211.

SHIU, L. P., \& PASHLER, H. (1994). Negligible effect of spatial precuing on identification of single digits. Journal of Experimental Psychology: Human Perception \& Performance, 20, 1037-1054.

Shulman, G. L., Remington, R. W., \& McLean, J. P. (1979). Moving attention through visual space. Journal of Experimental Psychology: Human Perception \& Performance, 5, 522-526.

SPERLING, G., \& WeICHSElGarTNER, E. (1995). Episodic theory of the dynamics of spatial attention. Psychological Review, 102, 503-532.

Steinman, S. S., Steinman, B. A., Trick, G. L., \& Lehmkuhle, S. L. (1994). A sensory explanation for visual attention deficits in the elderly. Optometry \& Vision Science, 71, 743-749.

TOWNSEND, J. T., \& ASHBY, F. G. (1983). Stochastic modeling of elementary psychological processes. New York: Cambridge University Press.

TSAL, Y. (1983). Movements of attention across the visual field. Journal of Experimental Psychology: Human Perception \& Performance, 9, 523-530.

WECHSLER, D. (1981). Wechsler Adult Intelligence Scale-Revised. New York: Psychological Corporation.

Whiting, W. L., \& Smith, A. D. (1997). Differential age-related processing limitations in recall and recognition tasks. Psychology \& Aging, 12, 216-224.

WiLcox, R. R. (1996). Statistics for the social sciences. San Diego: Academic Press.

YANTIS, S., \& JONIDES, J. (1990). Abrupt visual onsets and selective attention: Voluntary versus automatic allocation. Journal of Experimental Psychology: Human Perception \& Performance, 16, 121-134.

\section{NOTES}

1. Eriksen and Murphy (1987) pointed out shortcomings in the methodologies and interpretations of Remington and Pierce (1984), Shulman et al. (1979), and Tsal (1983), chiefly concerning the failure to allow for effects of retinal eccentricity and generalized warning effects. On the basis of reanalyses of the data, they suggested that, contrary to the conclusions of the original studies, the Shulman et al. data were consistent with noninertial effects and the Remington and Pierce data suggested inertial effects. We cite the above studies chiefly for illustrative purposes.

2. In order to test $H_{0}: \tau=0$, the critical $\tau$ for $(n=4, \alpha=.05)$ is .96 (Wilcox, 1996). Therefore, a more rigorous test of the null hypothesis would require a larger number of data points $(n \approx 8)$ per observer. The critical comparison in the present experiment is not between the obtained $\tau$ and the $\tau$ under the null ( 0 ), but rather the obtained values for $\tau$ across the different metrics.

(Manuscript received September 26, 1997; revision accepted for publication May 3,1998 .) 